\title{
Influence of Cellular Lipids on Cryopreservation of Mammalian Oocytes and Preimplantation Embryos: A Review
}

\author{
Sergei Amstislavsky, ${ }^{1}$ Valentina Mokrousova,,2 Eugeny Brusentsev, \\ Konstantin Okotrub, ${ }^{3}$ and Pierre Comizzoli ${ }^{4}$
}

Lipids are among the most abundant and essential cell components. Specifically, cytoplasmic lipid droplets (LDs) play crucial roles in cellular energy homeostasis. The foci of this review are (1) the composition and roles of lipids during oocyte maturation and early embryonic development, (2) possible causes of cryoinjuries in lipid-rich oocytes/embryos, and (3) ways to overcome these detrimental effects. Recent reports show that LDs in oocytes and embryos are not only energy depots but also are active organelles, possessing many other functions. In addition, analysis of the current literature confirms that lipid phase transition followed by phase separation during cryopreservation is one of the major causes of cryodamage in lipid-rich oocytes and embryos. While LDs and cell membranes are sensitive to chilling and freezing conditions, recent advances in vitrification and delipidation of lipid-rich oocytes and embryos partly mitigate cryodamage. The multidisciplinary approach is critical to reveal mechanisms underlying cryodamage and provides a theoretical basis for optimal cryopreservation of lipid-rich oocytes/embryos.

Keywords: lipid droplets, oocytes, preimplantation embryo, cryopreservation

\section{Introduction}

$\mathrm{L}$ IPIDS ARE AMONG the most abundant and essential chemical components of cells, playing important roles in their structure, metabolism, and regulation. ${ }^{1-3}$ Lipid droplets (LDs), such as cytoplasmic membranes, are sensitive to nonphysiological temperatures; thus, they can be affected by cryopreservation. ${ }^{4-6}$ Cytoplasmic membranes are phospholipid bilayers, which are thought to be the primary target of cryoinjuries. ${ }^{6,7}$ However, cytoplasmic LDs have different functions and structures. They contain lipids for energy storage $^{8}$ with a hydrophobic core surrounded by a phospholipid monolayer, mostly consisting of triacylglycerols (TGs) and sterol esters, such as cholesterol. ${ }^{1}$ LDs are regarded as active organelles playing crucial roles in cellular energy homeostasis. ${ }^{1,3}$ Specifically, LDs operate in coordination with endoplasmic reticulum (ER), mitochondria, and other subcellular elements. ${ }^{3}$

In addition to energy homeostasis, recent findings demonstrate the involvement of LDs in cell protection, regulation of protein metabolism, and nuclear functions. ${ }^{3}$ Importantly, LD concentration is associated with the capability of oocytes and embryos to survive after cryopreservation. ${ }^{9,10}$ Some livestock species ${ }^{10}$ and carnivores ${ }^{11}$ have lipid-rich embryos and oocytes, which are challenging to freeze. The understanding of mechanisms underlying higher cryosensitivity of lipid-rich oocytes/embryos would assist genome resource banking (GRB) efforts concerning these key species. This review is focused on (1) the composition of lipids and their functions during oocyte maturation and early embryonic development, (2) possible causes of cryoinjuries in lipid-rich oocytes/embryos, and (3) ways to overcome these detrimental effects.

\section{Structure, Composition, and Roles of Lipids in Oocytes and Embryos: Emphasis on LDs}

It is well known that oocytes, as well as cumulus cells of some Ruminantia and Carnivora species, contain high

\footnotetext{
${ }^{1}$ Department of Cryopreservation and Reproductive Technologies, Institute of Cytology and Genetics, Siberian Branch of the Russian Academy of Sciences, Novosibirsk, Russia.

${ }^{2}$ Department of Natural Sciences, Novosibirsk State University, Novosibirsk, Russia.

${ }^{3}$ Laboratory of Condensed Matter, Institute of Automation and Electrometry, Siberian Branch of the Russian Academy of Sciences, Novosibirsk, Russia.

${ }^{4}$ Center of Species Survival, Smithsonian Conservation Biology Institute, Smithsonian National Zoological Park, Washington, District of Columbia.
} 
concentrations of LDs. ${ }^{2}$ In mammalian species studied so far, LD diameters in oocytes and early embryos usually vary from 0.1 to $1.0 \mu \mathrm{m},{ }^{12,13}$ and they can reach up to $5-6 \mu \mathrm{m}$ or even larger at later embryonic stages. ${ }^{14}$

In mammalian oocytes, LDs contain triglycerides, phospholipids, cholesterol, free fatty acids, and proteins. ${ }^{2,15}$ The contents of triglycerides, phospholipids, and cholesterol in LDs decrease significantly during the maturation of porcine oocytes but remain unchanged from zygote up to the morula stage. ${ }^{15}$ Thereafter, at the blastocyst stage, the levels of triglycerides and phospholipids decrease. ${ }^{15}$ LDs are also associated with other organelles involved in cellular metabolism. Previous studies based on conventional light and electron microscopy revealed close spatial relationships among ER, mitochondria, and LDs in immature bovine oocytes; these clusters were termed metabolic units. ${ }^{16}$ The close association of these different organelles facilitates cellular metabolism. Upon activation, lipase-mediated hydrolysis of TG in LDs ends up in the release of free fatty acids. Intracellular free fatty acids then become available for metabolism via betaoxidation in mitochondria within the same metabolic unit. ${ }^{2,17}$

Staining with permeable lipophilic fluorophores borondipyrromethene and Nile Red followed by fluorescence microscopy or confocal laser scanning microscopy is a routine method for localizing and imaging LDs in mammalian oocytes. ${ }^{2,18}$ Advanced microscopy techniques such as Förster resonance energy transfer (FRET) provide high resolution (tens of nanometers) and are very helpful in studying LD biology. ${ }^{12,17}$ FRET analysis ${ }^{17}$ confirmed that in immature and mature porcine oocytes, most LDs are associated with mitochondria. These advanced approaches combined with traditional light microscopy and transmission electron microscopy ${ }^{19}$ allowed exploration of LD shape and location in oocytes and embryos.

The spatial distribution of LDs in the cytoplasm differs between immature and mature metaphase II stage oocytes and is species-specific. ${ }^{2}$ For instance, in pigs, LDs are distributed uniformly in immature oocytes and mostly peripherally after in vitro maturation. ${ }^{17}$ However, LDs in immature mouse oocytes have a homogeneous distribution and tend to aggregate centrally during maturation. ${ }^{2}$

There are species-specific features regarding lipid content, the degree of lipid saturation, and the profile of fatty acids in oocytes or embryos ${ }^{2,20}$ (Table 1 ). They determine, to a large extent, the dark view of some oocytes in bright-field microscopy. ${ }^{2}$ Oocytes and embryos of Carnivora and Artiodactyla species are known to be lipid-rich. ${ }^{2,11}$ In the domestic cat, oocytes and preimplantation embryos appear darker under a bright-field microscope than in the mouse or rat. The cause of this phenomenon is that cat oocytes absorb more light because of the higher quantity of LDs (Fig. 1). The results presented in Table 1 are based on drying and weighing and (mostly) on unparalleled gas chromatography estimation of lipid profiles in oocytes/one-cell embryos and on summarizing the analyses of 100-4000 pooled cells from seven mammalian species. TG is the main form of accumulating neutral lipids inside LDs in all mammalian cells studied so far. ${ }^{3,21}$

Human oocytes are characterized by the highest percentages of saturated lipids among species studied so far, whereas the highest contents of unsaturated lipids are found in mouse and rat oocytes. ${ }^{22-24}$ Surprisingly, the proportion of unsaturated lipids in feline oocytes, according to our own observations, ${ }^{25}$ is very high and close to that in mouse and rat oocytes (Table 1). Of the 12 studied fatty acids in oocytes of the species represented in Table 1, oleic acid, palmitic acid, stearic acid, and arachidonic acid are the most common. Oocytes of the listed species are poor in such fatty acids as myristic acid (sheep), stearic acid (rabbit), linolenic acid (cow, pig, and human), and lignoceric acid (rat and mouse). Although stearic acid is the most abundant in human oocytes, it is the scarcest in rabbit oocytes.

A reduced amount of lipids in oocytes (revealed optically by a pale appearance) in "lipid-rich" species (domestic dog or cattle) is usually a sign of oocyte degeneration. ${ }^{26,27}$ In contrast, dark-looking ooplasm in bovine oocytes points to an accumulation of lipids and is a mark of good developmental potential. ${ }^{27}$ It was found that the ratios of different fatty acids differed in bovine oocytes of different grades: oleic acid along with palmitic acid were the most abundant fatty acids in high-quality, fresh and frozen-thawed immature and in vitro matured oocytes, whereas stearic and palmitic acids dominated in low-quality oocytes. ${ }^{21}$ Moreover, the lipid composition of oocytes can be significantly affected by seasons: phospholipids constitute about $80 \%$ of saturated fatty acids during summer in bovine immature oocytes, whereas their fraction is only $40 \%$ during winter. ${ }^{28}$

LDs serve as a depot of intracellular lipids in oocytes and embryos with beta-oxidation affecting the subsequent developmental potential. ${ }^{29}$ It has been reported that fatty acids play an important role in bovine embryo development in vivo. ${ }^{30}$ The researchers speculate that this change of embryonic lipids is critical for prostaglandin synthesis and thus plays a role in the embryo-mother dialogue. Moreover, whole-body metabolic stress compromises fertility, and this fact is associated with modified fatty acid profiles in the follicle in dairy cows with negative energy balance. ${ }^{31,32}$ The role of LDs in steroidogenic and eicosanoid pathways has also been conjectured. ${ }^{33}$

\section{Changes of Lipid Structure and Properties During Chilling and Cryopreservation}

Difficulties in freezing oocytes and preimplantation embryos with high lipid content have already been known for $>40$ years, ${ }^{4}$ and they are still a major limitation in many mammalian species. ${ }^{34,35}$ Mechanisms of cryodamage in lipid-rich oocytes/embryos remain poorly studied. For instance, LDs tend to aggregate and enlarge during chilling of porcine blastocysts to $+15^{\circ} \mathrm{C},{ }^{4}$ which leads to embryonic death.

Along with methods previously described, such as various microscopy procedures, cellular changes during freezing can be monitored by vibrational spectroscopy, which can be considered under some circumstances a noninvasive label-free method suitable for in vitro live cell monitoring and evaluation of lipid unsaturation degree. ${ }^{12,25}$ It can also be used to study lipid phase transition (LPT) ${ }^{6}$ and to analyze the ordering and conformational states of lipid structures, ${ }^{36}$ at a resolution comparable with the resolution of confocal microscopes.

To the best of our knowledge, no studies have addressed interactions between cryoprotectants (CPAs) and LDs. Cryopreservation of lipid-rich oocytes and preimplantation embryos is performed with highly permeable CPAs, such as ethylene glycol, sometimes in combination with dimethyl sulfoxide and propylene glycol. ${ }^{37,38}$ It should be noted that the choice of CPAs for the cryopreservation of lipid-rich oocytes/embryos is still empirical. 


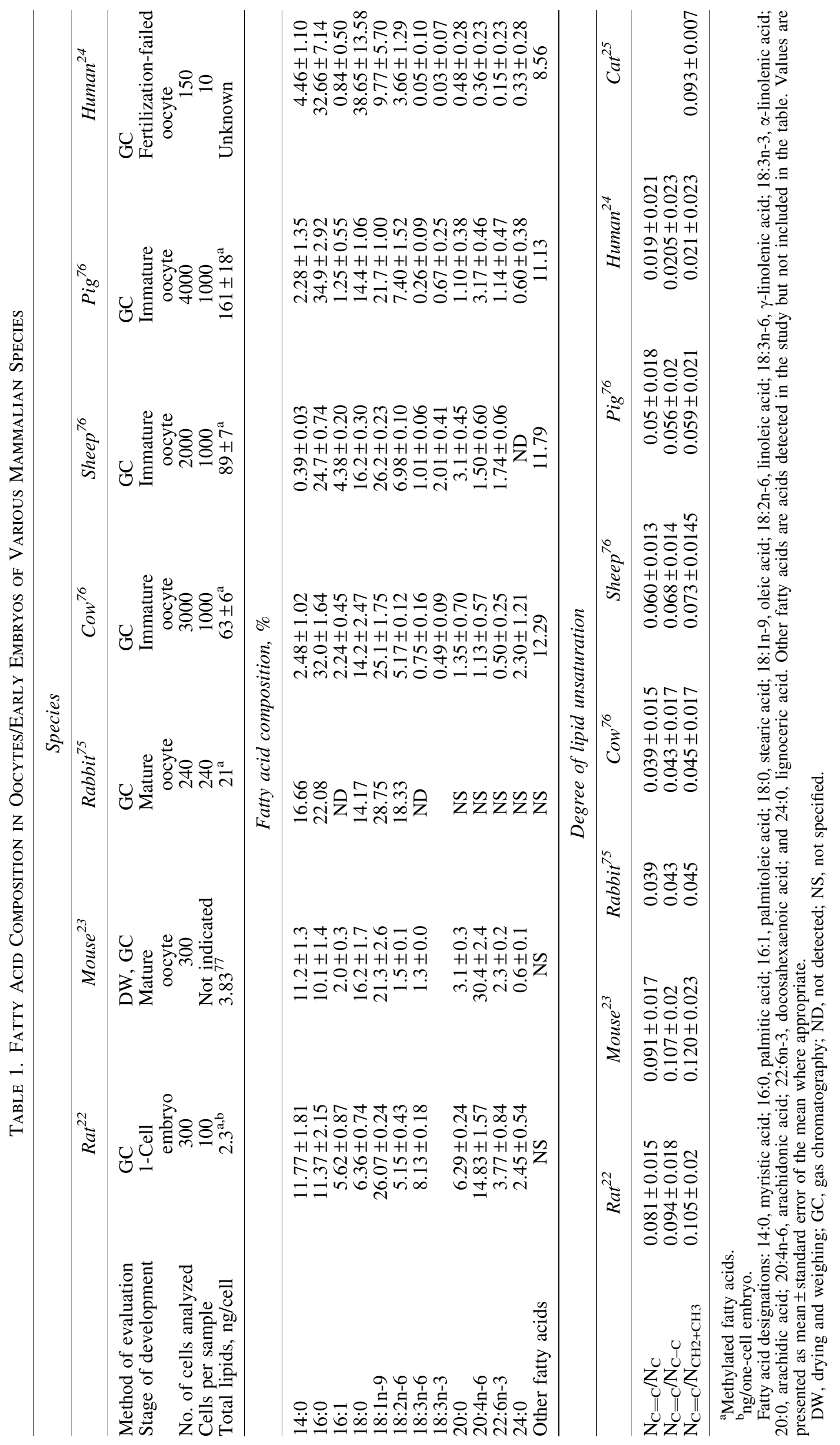



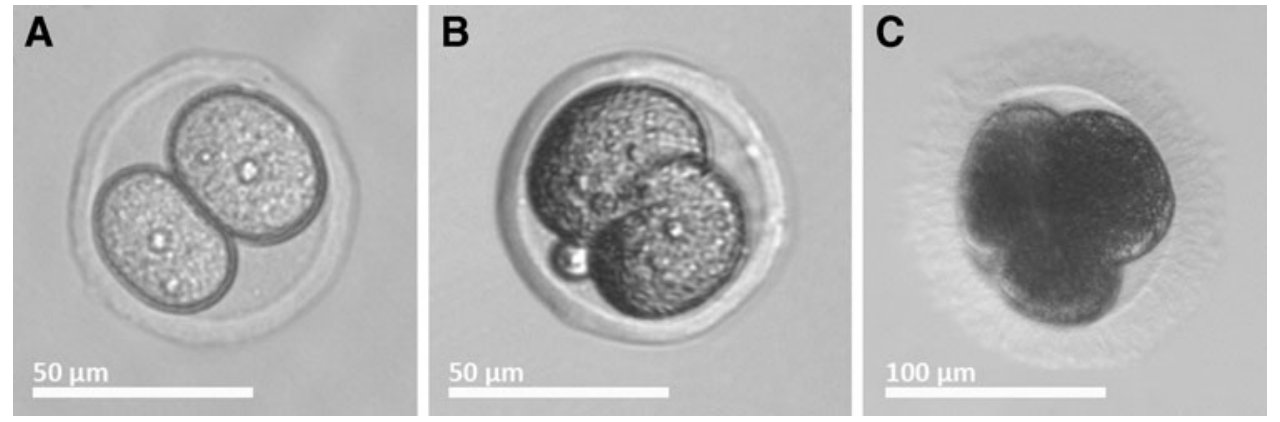

FIG. 1. Light micrographs of early-stage embryos demonstrating the effect of light attenuation by lipid droplets. Embryos are arranged in the order from low to high lipid content: (A) Wistar Albino Glaxo rat two-cell embryo. (B) Accelerated senescence catatonic mouse two-cell embryo. (C) Domestic cat three-cell embryo.

Lipid phase transition is believed to be the main source of cell damage at chilling temperatures below the temperature optimum but above the freezing point. Phase transition temperatures are different in different germplasms and species. It was reported that LPT for immature ovine oocytes ranges between $15^{\circ} \mathrm{C}$ and $20^{\circ} \mathrm{C}$. ${ }^{39}$ However, for four- to eight-cell stage mouse embryos, LPT occurs at temperatures within $-7^{\circ} \mathrm{C}$ to $0^{\circ} \mathrm{C} .^{40}$ This process also depends on season, diet, and other factors. ${ }^{28,39}$ Phase separation can also happen as a result of phase transitions in cell membranes and LDs containing mixtures of lipids with different lengths of acyl chains and different numbers of double carbon bonds. Correlation between the LD pattern and embryo cryosensitivity has been demonstrated by in vitro studies. In vitro-produced (IVP) bovine embryos contain different concentrations and sizes of LDs depending on culture media. ${ }^{14}$ The numbers of giant $(>6 \mu \mathrm{m})$ LDs are significantly larger at morula and blastocyst stages when embryos are cultured in calf serum-supplemented media, and this phenomenon is accompanied by poor cryotolerance of such embryos. ${ }^{14}$

Phase transitions are physical phenomena underlying most problems of cell cryopreservation. LPT may change and disrupt intracellular processes and cause redistribution of phospholipids in membranes resulting in their injuries. ${ }^{5}$ Lipids in biological membranes, including LD surface, are generally in the liquid-disordered (fluid) phase at physiological temperatures, and their high elasticity prevents membrane rupture. ${ }^{41}$ Below the main LPT, cell membranes are supposed to turn to solid-like-ordered phases, in which the diffusion rate for hydrophobic molecules, as well as the permeability of membranes, decreases, ${ }^{42}$ and the membranes become more rigid. $^{41}$

Raman spectroscopy was used in our recent work with domestic cat oocytes and embryos. It was found that LPT occurred at about $-2^{\circ} \mathrm{C}$ in all the three categories of studied cells: immature oocytes, in vitro matured oocytes, and IVP embryos. $^{25}$ The reported LPT temperatures correlated with the degree of lipid saturation for oocytes. Oocytes and embryos rich in unsaturated lipids, as in mice and cats (Table 1), undergo LPT at lower temperatures ${ }^{25,40}$ than those containing higher proportions of saturated lipids, for example, bovine ${ }^{28}$ or ovine. ${ }^{39}$ This relatively low-temperature LPT may explain the high rates of embryo freezing success in mice ${ }^{43}$ and relatively high rates of preimplantation embryo freezing success in domestic cats ${ }^{44}$ despite the higher amount of lipids in embryos of the latter species.

As a result of phase transitions and redistribution of lipids inside LDs, functional disruption of organelles normally interacting with these LDs (ER and mitochondria) may happen, as hypothesized by Sudano et al. ${ }^{45}$ To mitigate these negative effects of chilling on lipid-rich oocytes and embryos, partial delipidation and/or lipolysis, vitrification, and special conditions of in vitro culture (IVC) may be recommended as described below (see "Mitigating Detrimental Effects of Lipids During Oocyte and Embryo Cryopreservation”).

\section{Mitigating Detrimental Effects of Lipids During Oocyte and Embryo Cryopreservation}

Various approaches, such as delipidation (partial removal of LDs), polarization of LDs in cells by centrifuging, lipolysis, and chemical modification of lipid profiles, have been attempted to increase the effectiveness of cryopreservation in lipid-rich oocytes/embryos. Normally, these procedures are applied either to oocytes or to cleavage stage embryos up to morula stage. ${ }^{9,46-48}$ However, to the best of our knowledge, there is no report on blastocyst delipidation. Usually, blastocysts are vitrified without additional manipulations.

The survival rate after cryopreservation exceeded $50 \%$ for delipidated two- to four-cell or four- to eight-cell porcine embryos; however, no surviving embryos were reported if this procedure was omitted. ${ }^{9}$ Interestingly, lipid removal in feline zygotes had no apparent effects on survival of IVP cat blastocysts after cryopreservation. ${ }^{49}$ It should be noted that the redistribution of LDs by polarization may adversely affect the subsequent development of oocyte/embryo cryopreservation. ${ }^{47,48}$ After embryo culturing, at least in pigs, polarization returns to uniform LD distribution across the cytoplasm. However, cryopreservation interferes with this process, and it is conjectured that the freeze/thaw process alters the physicochemical properties of intracellular lipids. ${ }^{50}$

Some chemicals, most often forskolin, are used as an alternative to mechanical delipidation. ${ }^{51,52}$ Partial delipidation with forskolin increased the survival of porcine blastocysts after vitrification ${ }^{51}$ and the survival two- to eight-cell stages of cat embryos after controlled-rate freezing. ${ }^{52}$

It has been demonstrated that the lipid composition of oocytes and cumulus cells changes when linoleic acid is added to the maturation medium for bovine oocytes. ${ }^{53}$ Supplementation of maturation/culture media with linoleic acid improved in vitro development after cryopreservation procedures, as reported in experiments with sheep blastocysts ${ }^{34}$ and cattle mature oocytes. ${ }^{54}$ It has been demonstrated that IVC of bovine embryos in media supplemented with conjugated isomer of linoleic acid, trans-10, cis-12 octadecadienoic acid (t10, c12 CLA), improved survival after vitrification. ${ }^{55}$ It was shown in these experiments that the addition of t10, c12 CLA to serum-containing media decreased embryo cytoplasmic lipid deposition. ${ }^{55}$ Alternatively, the cytoplasmic lipid content can be reduced with phenazine ethosulfate (PES), a 
compound that oxidizes nicotinamide adenine dinucleotide phosphate (NADPH). ${ }^{56}$ Treatment with PES intensifies glucose metabolism, reduces the accumulation of medium- and large-size LDs in the cytoplasm of bovine embryos produced in vitro, ${ }^{57}$ and improves their cryotolerance. ${ }^{56}$

An attempt of in vivo modification of oocyte lipid content in animals receiving specialized diets was undertaken with ewes. ${ }^{39}$ It has been shown that a diet rich in polyunsaturated fatty acids preserves the integrity of immature oocyte membranes during chilling and reduces the midpoint temperature of LPT. ${ }^{39}$ Post-thaw cleavage rates increase when bovine oocytes are preincubated with cholesterol-loaded methyl-b-cyclodextrin (CLC). ${ }^{58}$ It is noteworthy that a high concentration of cholesterol in membranes reduces sensitivity to cooling. ${ }^{58}$ Cholesterol from CLC readily enters cumulus cells and oocytes and improves survival in chemically determined vitrification systems. ${ }^{58}$

\section{Vitrification as a Possibility to Cryopreserve Lipid-Rich Oocytes and Embryos}

Conventional controlled-rate freezing is an equilibration process, which is characterized by low cooling rates to keep intracellular water supercooled while promoting the movement of water from intracellular to extracellular compartments where it will freeze. ${ }^{59}$ An alternative approach for cryopreservation of oocytes and embryos is vitrification, which was first implemented by Luyet and Hodapp for sperm cryopreservation ${ }^{60}$ and then successfully applied to mammalian embryos in the 1980s. ${ }^{61}$

Nowadays, vitrification is specified as equilibrium and nonequilibrium. ${ }^{62}$ Nonequilibrium (kinetic) vitrification requires lower concentrations of CPAs than equilibrium but higher cooling rates, while complete transition to glass and achievement of the ice-free state of extracellular contents are unnecessary in this case. ${ }^{62}$ In a vast majority of mammalian species, vitrification is more effective in oocytes and/or preimplantation embryos rich in lipids, such as pigs, and with scarcer LDs, such as cattle and sheep (Table 2). Use of vitrification for these species may solve issues associated with chilling by applying faster cooling compared with slow freezing.

Permeating and nonpermeating CPAs in moderate concentrations are used for controlled-rate freezing. The same types of CPAs are used for ultra-rapid freezing and vitrification, but their concentrations are usually two- or threefold higher, ${ }^{63}$ with the exception of kinetic vitrification, where much lower concentrations of CPAs are required. ${ }^{62} \mathrm{Vi}^{-}$ trification normally demands much higher cooling rates than slow freezing. ${ }^{45}$ The volume and viscosity of solutions are also of great importance for achieving vitrification. ${ }^{64}$ However, vitrification has some drawbacks. In particular, many of modern vitrification protocols assume an open interaction between vitrified samples and liquid nitrogen; therefore, contamination of samples via liquid nitrogen is possible. ${ }^{65}$ Contamination can be prevented by using closed systems or sterile liquid nitrogen. Although methods and equipment for sterile filtration of liquid nitrogen exist, ${ }^{66}$ this approach is rarely used in practical cell banking. Moreover, vitrified samples require stricter temperature control during cryostorage and much higher rates of warming compared with conventionally frozen ones. ${ }^{67}$ Exposure of oocytes and embryos to high concentrations of CPAs used for vitrification may exert toxic effects. ${ }^{6}$

\section{Adapted Warming and Thawing Methods}

Thawing/warming is an important part of survival after cryopreservation. Generally, slow cooling needs slow thawing and fast cooling needs faster thawing. ${ }^{59,69}$ Thawing rates for conventionally frozen oocytes and embryos usually vary from $20^{\circ} \mathrm{C} / \mathrm{min}$ up to 300 or even $2500^{\circ} \mathrm{C} / \mathrm{min} .{ }^{69}$ Normally, vitrified samples need higher warming rates. To avoid devitrification and formation of ice crystals, warming rates should be also very high; it depends on container and warming strategy. ${ }^{63,64}$ Novel warming methods were recently developed. ${ }^{70,71}$ Lipid-rich zebrafish embryos were

Table 2. Recent Results of Oocyte and Embryo Cryopreservation in Mammalian Species WITH DifFERENT AMOUNTS OF INTRACELlular LiPIDS

\begin{tabular}{|c|c|c|c|c|c|}
\hline Species & Amount of lipid & Developmental stage & Cryopreservation & Viability, \% & Survival assessment ${ }^{\mathrm{a}}$ \\
\hline Pig & +++ & $\begin{array}{l}\text { Oocytes } \\
\text { Embryos }\end{array}$ & $\begin{array}{l}\text { Vitrification } \\
\text { Vitrification }\end{array}$ & $\begin{array}{l}90 \\
28.6\end{array}$ & $\begin{array}{l}\text { Morphology evaluation } \\
\text { Birth rate }\end{array}$ \\
\hline Sheep & ++ & $\begin{array}{l}\text { Oocytes } \\
\text { Embryos }\end{array}$ & $\begin{array}{l}\text { Vitrification } \\
\text { Vitrification }\end{array}$ & $\begin{array}{l}85.78 \\
52.0\end{array}$ & $\begin{array}{l}\text { Morphology evaluation } \\
\text { Implantation rate }\end{array}$ \\
\hline Cattle & ++ & $\begin{array}{l}\text { Oocytes } \\
\text { Embryos }\end{array}$ & $\begin{array}{l}\text { Vitrification } \\
\text { Vitrification }\end{array}$ & $\begin{array}{l}56.0 \\
50\end{array}$ & $\begin{array}{l}\text { CaAM/EthD-1 staining } \\
\text { Birth rate } \\
{ }^{82}\end{array}$ \\
\hline Rabbit & ++ & $\begin{array}{l}\text { Oocytes } \\
\text { Embryos }\end{array}$ & $\begin{array}{l}\text { Slow freezing } \\
\text { Vitrification }\end{array}$ & $\begin{array}{l}14.5 \\
29\end{array}$ & $\begin{array}{l}\text { Implantation rate } \\
\text { Birth rate }\end{array}$ \\
\hline Mouse & + & $\begin{array}{l}\text { Oocytes } \\
\text { Embryos }\end{array}$ & $\begin{array}{l}\text { Vitrification } \\
\text { Vitrification }\end{array}$ & $\begin{array}{l}87.5 \\
79\end{array}$ & $\begin{array}{l}\text { Morphology evaluation } \\
\text { Birth rate }\end{array}$ \\
\hline Rat & + & $\begin{array}{l}\text { Oocytes } \\
\text { Embryos }\end{array}$ & $\begin{array}{l}\text { Vitrification } \\
\text { Vitrification }\end{array}$ & $\begin{array}{l}82.7 \\
63\end{array}$ & $\begin{array}{l}\text { Morphology evaluation } \\
\text { Birth rate }\end{array}$ \\
\hline Human & Unknown & $\begin{array}{l}\text { Oocytes } \\
\text { Embryos }\end{array}$ & $\begin{array}{l}\text { Vitrification } \\
\text { Vitrification }\end{array}$ & $\begin{array}{l}94.5 \\
46.7\end{array}$ & $\begin{array}{l}\text { Morphology evaluation } \\
\text { Birth rate }\end{array}$ \\
\hline
\end{tabular}

${ }^{a}$ Morphology evaluation: oocytes exhibiting normal volume and size of the perivitelline space, with a spherical and symmetrical shape and evenly granulated cytoplasm with no sign of lysis, membrane, or zona pellucida damage; swelling; vacuolization; degeneration; or leakage of the cellular content were considered viable. Birth rate was calculated as the ratio of the number of the total offspring born and the number of embryos transferred to all recipients. 
vitrified and then exposed to laser heating; golden nanorods were injected to these embryos to enhance absorbance of laser radiation to achieve $1.4 \times 10^{7} \mathrm{C} / \mathrm{min}$ rate of warming, thus to avoid devitrification with subsequent recrystallization. The application of these methods to lipid-rich mammalian embryos is a matter of the near future. ${ }^{70,72,73}$

\section{Conclusions}

The composition of LDs might be influenced by culture conditions because the latter affect the size and other properties of LDs in IVP embryos. This is particularly true for oocyte maturation and early embryonic development in vitro.

There is evidence for an important role of cellular lipids in the cryopreservation of oocytes and early embryos. In particular, the lack of knowledge about the cryobiological behavior of cellular lipids, that is, cellular membranes and LDs, hampers the use of the GRB concept for domestic and nondomestic animals with lipid-rich oocytes and embryos. ${ }^{74}$ The survival of embryos after cryopreservation is a multifactorial process influenced by lipid content, lipid composition, embryo metabolism, apoptosis rate, and the overall gene expression. ${ }^{4}$ There are indications that lipid abundance aggravates the cryopreservation of oocytes and preimplantation embryos.

Recent advances in vitrification partly mitigate these problems, but not in all cases. A useful tool to overcome these difficulties is partial delipidation. Nevertheless, understanding the behavior of lipids during chilling and freezing, in particular, lipid phase transitions, is critical for successful cryopreservation.

Over the past decades, the GRB concept has been applied to preservation of valuable genotypes in several wildlife and domestic mammalian species. However, the application of this concept to some species is limited by the lack of fundamental cryobiological knowledge and species-specific features. $^{74}$ Multidisciplinary approaches, including spectroscopy and microscopy, may reveal the mechanisms underlying cryodamage and provide a theoretical basis for optimal cryopreservation of lipid-rich oocyte/embryo cryopreservation.

\section{Acknowledgments}

Our studies mentioned in the text were supported by the Institute of Cytology and Genetics, project 0324-2018-0016, and by the Russian Foundation for Basic Research, project 16-04-01221. The authors are grateful to Victor Gulevich for linguistic check.

\section{Author Disclosure Statement}

No competing financial interests exist.

\section{References}

1. Walther TC, Farese RV. The life of lipid droplets. Biochim Biophys Acta 2009;1791:459-466.

2. Dunning KR, Russell DL, Robker RL. Lipids and oocyte developmental competence: The role of fatty acids and $\beta$ oxidation. Reproduction 2014;148:15-27.

3. Welte MA, Gould AP. Lipid droplet functions beyond energy storage. Biochim Biophys Acta 2017;1862:1260-1272.

4. Polge C. The freezing of mammalian embryos: Perspectives and possibilities. Ciba Found Symp 1977;52:3-18.
5. Quinn PJ. A lipid-phase separation model of lowtemperature damage to biological membranes. Cryobiology 1985;22:128-146.

6. Sieme H, Oldenhof H, Wolkers WF. Sperm membrane behaviour during cooling and cryopreservation. Reprod Domest Anim 2015;50:20-26.

7. Zeron Y, Tomczak M, Crowe J, Arav A. The effect of liposomes on thermotropic membrane phase transitions of bovine spermatozoa and oocytes: Implications for reducing chilling sensitivity. Cryobiology 2002;45:143-152.

8. Thiam AR, Farese RV Jr, Walther TC. The biophysics and cell biology of lipid droplets. Nat Rev Mol Cell Biol 2013; 14:775.

9. Nagashima H, Kashiwazaki N, Ashman RJ, et al. Cryopreservation of porcine embryos. Nature 1995;374:416.

10. Pereira RM, Marques CC. Animal oocyte and embryo cryopreservation. Cell Tissue Bank 2008;9:267-277.

11. Apparicio M, Ferreira CR, Tata A, et al. Chemical composition of lipids present in cat and dog oocyte by matrix-assisted desorption ionization mass spectrometry (MALDI-MS). Reprod Domest Anim 2012;47(s6):113-117.

12. Daemen S, van Zandvoort MA, Parekh SH, Hesselink MK. Microscopy tools for the investigation of intracellular lipid storage and dynamics. Mol Metab 2015;5:153-163.

13. Bradley J, Pope I, Masia F, et al. Quantitative imaging of lipids in live mouse oocytes and early embryos using CARS microscopy. Development 2016;143:2238-2247.

14. Abe H, Yamashita S, Satoh T, Hoshi H. Accumulation of cytoplasmic lipid droplets in bovine embryos and cryotolerance of embryos developed in different culture systems using serum-free or serum-containing media. Mol Reprod Dev 2002;61:57-66.

15. Romek M, Gajda B, Krzysztofowicz E, Kepczynski M, Smorag Z. New technique to quantify the lipid composition of lipid droplets in porcine oocytes and pre-implantation embryos using Nile Red fluorescent probe. Theriogenology 2011;75:42-54.

16. Kruip TA, Cran DG, Van Beneden TH, et al. Structural changes in bovine oocytes during final maturation in vivo. Mol Reprod Dev 1983;8:29-47.

17. Sturmey RG, O'Toole PJ, Leese HJ. Fluorescence resonance energy transfer analysis of mitochondrial: Lipid association in the porcine oocyte. Reproduction 2006;32:829-837.

18. Aardema H, Vos PL, Lolicato F, et al. Oleic acid prevents detrimental effects of saturated fatty acids on bovine oocyte developmental competence. Biol Reprod 2011;85: 62-69.

19. Ordonez-Leon EA, Merchant H, Medrano A, et al. Lipid droplet analysis using in vitro bovine oocytes and embryos. Reprod Domest Anim 2014;49:306-314.

20. Genicot G, Leroy JLMR, Van Soom A, et al. The use of a fluorescent dye Nile red to evaluate the lipid content of single mammalian oocytes. Theriogenology 2005;63:11811194.

21. Kim JY, Kinoshita M, Ohnishi M, et al. Lipid and fatty acid analysis of fresh and frozen-thawed immature and in vitro matured bovine oocytes. Reproduction 2001;122: 131-138.

22. Khandoker M, Tsujii H, Karasawa D. Fatty acid composition of blood serum, oocytes, embryos and reproductive tract fluids of rat and comparison with BSA. Anim Sci Technol 1997;68:1070-1074.

23. Wang G, Tsujii H, Khandoker MY. Fatty acid compositions of mouse embryo, oviduct and uterine fluid. Nihon Chikusan Gakkaiho 1998;69:923-928. 
24. Matorras R, Ruiz JI, Mendoza R, et al. Fatty acid composition of fertilization-failed human oocytes. Hum Reprod 1998;13:2227-2230.

25. Okotrub KA, Mokrousova VI, Amstislavsky S, Surovtsev NV. Lipid droplet phase transition in freezing cat embryos and oocytes probed by Raman spectroscopy. Biophys J 2018;115:577-587.

26. Durrant BS, Pratt NC, Russ KD, et al. Isolation and characterization of canine advanced preantral and early antral follicles. Theriogenology 1998;49:917-932.

27. Jeong WJ, Cho SJ, Lee HS, et al. Effect of cytoplasmic lipid content on in vitro developmental efficiency of bovine IVP embryos. Theriogenology 2009;72:584-589.

28. Zeron Y, Ocheretny A, Kedar O, et al. Seasonal changes in bovine fertility: Relation to developmental competence of oocytes, membrane properties and fatty acid composition of follicles. Reproduction 2001;121:447-454.

29. McKeegan PJ, Sturmey RG. The role of fatty acids in oocyte and early embryo development. Reprod Fertil Dev 2011;24:59-67.

30. Menezo Y, Renard JP, Delobel B, Pageaux JF. Kinetic study of fatty acid composition of day 7 to day 14 cow embryos. Biol Reprod 1982;26:787-790.

31. Vanholder T, Leroy JL, Soom AV, et al. Effect of nonesterified fatty acids on bovine granulosa cell steroidogenesis and proliferation in vitro. Anim Reprod Sci 2005; 87:33-44.

32. Leroy JL, Vanholder T, Mateusen B, et al. Non-esterified fatty acids in follicular fluid of dairy cows and their effect on developmentalcapacity of bovine oocytes in vitro. Reproduction 2005;130:485-495.

33. Prates EG, Nunes JT, Pereira RM. A role of lipid metabolism during cumulus-oocyte complex maturation: Impact of lipid modulators to improve embryo production. Mediators Inflamm 2014;2014:1-11.

34. Dobrinsky JR. Cryopreservation of swine embryos: A chilly past with a vitrifying future. Theriogenology 2001;56:13331344.

35. Romao R, Marques CC, Baptista MC, et al. Cryopreservation of in vitro-produced sheep embryos: Effects of different protocols of lipid reduction. Theriogenology 2015;84:118 126.

36. Da Silva E, Rousseau D. Molecular order and thermodynamics of the solid-liquid transition in triglycerides via Raman spectroscopy. Phys Chem Chem Phys 2008;10: 4606-4613.

37. Wu G, Jia B, Quan G, et al. Vitrification of porcine immature oocytes: Association of equilibration manners with warming procedures, and permeating cryoprotectants effects under two temperatures. Cryobiology 2017;75:21-27.

38. Gomez MC, Pope E, Harris R, et al. Development of in vitro matured, in vitro fertilized domestic cat embryos following cryopreservation, culture and transfer. Theriogenology 2003;60:239-251.

39. Zeron Y, Sklan D, Arav A. Effect of polyunsaturated fatty acid supplementation on biophysical parameters and chillingsensitivity of ewe oocytes. Mol Reprod Dev 2002;61: 271-278.

40. Okotrub KA, Amstislavsky SY, Surovtsev NV. Raman spectroscopy reveals the lipid phase transition in preimplantation mouse embryos during freezing. Arch Biochem Biophys 2017;635:37-43.

41. Lee CH, Lin WC, Wang J. All-optical measurements of the bending rigidity of lipid-vesicle membranes across structural phase transitions. Phys Rev E 2001;64:020901.
42. Papahadjopoulos D, Jacobson K, Nir S, Isac T. Fluorescence polarization and permeability measurements concerning the effect of temperature and cholesterol. Biochim Biophys Acta 1973;311:330-348.

43. Igonina TN, Brusentsev EY, Rozhkova IN, Naprimerov VA, Amstislavsky SY. A comparison of different cryoprotectant solutions and thawing methods for the cryopreservation of embryos of mice and rats. Russ J Genet Appl Res 2016;6:378-382.

44. Pope CE. Aspects of in vivo oocyte production, blastocyst development, and embryo transfer in the cat. Theriogenology 2014;81:126-137.

45. Sudano MJ, Marinho LSR, Costa CB, Cancian R. Cryopreservation of bovine embryos. In: Seneda M, SilvaSantos K, Marinho LSR (eds). Biotechnology of Animal Reproduction. New York: Nova Science Publishers; 2016: 193-216.

46. Men H, Spate LD, Murphy CN, Prather RS. Cryopreservation of in vitro-produced early-stage porcine embryos in a closed system. Biores Open Access 2015;4:258-265.

47. Men $\mathrm{H}$, Zhao $\mathrm{C}, \mathrm{Si} \mathrm{W}$, et al. Birth of piglets from in vitroproduced, zona-intact porcine embryos vitrified in a closed system. Theriogenology 2011;76:280-289.

48. Galiguis J, Gomez MC, Leibo SP, Pope CE. Birth of a domestic 503 cat kitten produced by vitrification of lipid polarized in vitro matured oocytes. Cryobiology 2014;68: 459-466.

49. Karja NW, Otoi T, Wongsrikeao $\mathrm{P}$, et al. In vitro development and post-thaw survival of blastocysts derived from delipidated zygotes from domestic cats. Theriogenology 2006;65:415-423.

50. Isachenko V, Soler C, Isachenko E, et al. Vitrification of immature porcine oocytes: Effects of lipid droplets, temperature, cytoskeleton, and addition and removal of cryoprotectant. Cryobiology 1998;36:250-253.

51. Men H, Agca Y, Riley LK, Critser JK. Improved survival of vitrified porcine embryos after partial delipation through chemically stimulated lipolysis and inhibition of apoptosis. Theriogenology 2006;66:2008-2016.

52. Tharasanit T, Buarpung S, Manee-In S, et al. Birth of kittens after the transfer of frozen-thawed embryos produced by intracytoplasmic sperm injection with spermatozoa collected from cryopreserved testicular tissue. Reprod Domest Anim 2012;47:305-308.

53. Lapa M, Marques CC, Alves SP, et al. Effect of trans-10 cis-12 conjugated linoleic acid on bovine oocyte competence and fatty acid composition. Reprod Dom Anim 2011; 46:904-910.

54. Matos JE, Marques CC, Moura TF, et al. Conjugated linoleic acid improves oocyte cryosurvival through modulation of the cryoprotectantsinflux rate. Reprod Biol Endocrinol 2015;13:60.

55. Pereira RM, Carvalhais I, Pimenta J, et al. Biopsied and vitrified bovine embryos viability is improved by trans 10 , cis12 conjugated linoleicacid supplementation during in vitro embryo culture. Anim Reprod Sci 2008;106:322332.

56. Seidel GE Jr. Modifying oocytes and embryos to improve their cryopreservation. Theriogenology 2006;65:228-235.

57. De La Torre-Sanchez JF, Gardner DK, Preis K, et al. Metabolic regulation of in vitro-produced bovine embryos. II. Effects of phenazine ethosulfate, sodium azide and 2.4dinitrophenol during post-compaction development on glucose metabolism and lipid accumulation. Reprod Fertil Dev 2006;18:597-607. 
58. Horvath G, Seidel GE Jr. Vitrification of bovine oocytes after treatment with cholesterol-loaded methyl-beta-cyclodextrin. Theriogenology 2006;66:1026-1033.

59. Mazur P. Equilibrium, quasi-equilibrium, and nonequilibrium freezing of mammalian embryos. Cell Biophys 1990; $17: 53-92$.

60. Luyet BJ, Hodapp EL. Revival of frog's spermatozoa vitrified in liquid air. Proc Meet Soc Exp Biol 1938;36:433-434.

61. Rall WF, Fahy GM. Ice-free cryopreservation of mouse embryos at -196 degrees $C$ by vitrification. Nature 1985; 313:573-575.

62. Katkov II. Stopping biological clocks: The science and art of biopreservation. Bioprocess Int 2014;12:42-52.

63. Shaw JM, Jones GM. Terminology associated with vitrification and other cryopreservation procedures for oocytes and embryos. Hum Reprod Update 2003;9:583-605.

64. Saragusty J, Arav A. Current progress in oocyte and embryo cryopreservation by slow freezing and vitrification. Reproduction 2011;141:1-19.

65. Vajta G, Nagy ZP, Cobo A, et al. Vitrification in assisted reproduction: Myths, mistakes, disbeliefs and confusion. Reprod Biomed Online 2009;19:1-7.

66. Crook JM, Ludwig TE eds. Stem Cell Banking: Concepts and Protocols, Methods in Molecular Biology, vol. 1590 New York Humana Press; 2017.

67. Landel CP. Archiving mouse strains by cryopreservation. Lab Anim (NY) 2005;34:50-57.

68. Ledda S, Bogliolo L, Succu S, et al. Oocyte cryopreservation: Oocyte assessment and strategies for improving survival. Reprod Fertil Dev 2007;19:13-23.

69. Renard JP, Babinet C. High survival of mouse embryos after rapid freezing and thawing inside plastic straws with 1-2 propanediol as cryoprotectant. J Exp Zool 1984;230:443-448.

70. Khosla K, Wang Y, Hagedorn M, et al. Gold nanorod induced warming of embryos from the cryogenic state enhances viability. ACS Nano 2017;11:7869-7878.

71. Manuchehrabadi N, Gao Z, Zhang J, et al. Improved tissue cryopreservation using inductive heating of magnetic nanoparticles. Sci Transl Med 2017;9:4586.

72. Jin B, Kleinhans FW, Mazur P. Survivals of mouse oocytes approach $100 \%$ after vitrification in 3-fold diluted media and ultra-rapid warming by an IR laser pulse. Cryobiology 2014;68:419-430.

73. Jin B, Mazur P. High survival of mouse oocytes/embryos after vitrification without permeating cryoprotectants followed by ultra-rapid warming with an IR laser pulse. Sci Rep 2015;5:9271.

74. Comizzoli P, Holt WV. Recent advances and prospects in germplasm preservation of rare and endangered species. In: Holt WV, Brown JL, Comizzoli P (eds). Reproductive Sciences in Animal Conservation: Progress and Prospects (Advances in Experimental Medicine and Biology, vol. 753). New York: Springer Science; 2014: 331-356.

75. Khandoker MY, Tsujii H, Karasawa D. Fatty acid analysis of oocytes, oviductal and uterine fluids of rabbit. Anim Sci Technol 1996;67:549-553.

76. McEvoy TG, Coull GD, Broadbent PJ. Fatty acid composition of lipids in immature cattle, pig and sheep oocytes with intact zona pellucida. J Reprod Fertil 2000;118:163-170.

77. Loewenstein JE, Cohen AI. Dry mass, lipid content and protein content of the intact and zona-free mouse ovum. Development 1964;12:113-121.
78. Cuello C, Martinez CA, Nohalez A, et al. Effective vitrification and warming of porcine embryos using a $\mathrm{pH}$-stable, chemically defined medium. Sci Rep 2016;6:33915.

79. Quan GB, Wu GQ, Wang YJ, et al. Meiotic maturation and developmental capability of ovine oocytes at germinal vesicle stage following vitrification using different cryodevices. Cryobiology 2016;72:33-40.

80. Dos Santos-Neto PC, Cuadro F, Barrera N, et al. Embryo survival and birth rate after minimum volume vitrification or slow freezing of in vivo and in vitro produced ovine embryos. Cryobiology 2017;78:8-14.

81. Bulgarelli DL, Vireque AA, Pitangui-Molina CP, et al. Reduced competence of immature and mature oocytes vitrified by Cryotop method: Assessmentby in vitro fertilization and parthenogenetic activation in a bovine model. Zygote 2017;25:222-230.

82. Martinez AG, Valcarcel A, De Las Heras MA, et al. Vitrification of in vitro produced bovine embryos: In vitro and in vivo evaluations. Anim Reprod Sci 2002;73:11-21.

83. Jimenez-Trigos E, Vicente JS, Marco-Jimenez F. A novel technique for oviduct occlusion to generate live birthsfrom cryopreserved rabbit oocytes after in vivo fertilisation. Anim Reprod Sci 2014;148:197-204.

84. Naik BR, Rao BS, Vagdevi R, et al. Conventional slow freezing, vitrification and open pulled straw (OPS) vitrification of rabbit embryos. Anim Reprod Sci 2005;86:329338.

85. Karami A, Bakhtiari M, Azadbakht M, et al. Impact of prolonged oocyte incubation time before vitrification on oocyte survival, embryo formation, and embryo quality in mice. In Vitro Cell Dev Biol Anim 2017;53:525-531.

86. Mochida K, Hasegawa A, Otaka N, et al. Devising assisted reproductive technologies for wild-derived strains of mice: 37 strains from five subspecies of Mus musculus. PLoS One 2014;9:e114305.

87. Fujiwara K, Kamoshita M, Kato T, et al. Generation of rats from vitrified oocytes with surrounding cumulus cells via in vitro fertilization with cryopreserved sperm. Anim Sci J 2017;88:180-184.

88. Han MS, Niwa K, Kasai M. In vivo development of vitrified rat embryos: Effects of timing and sites of transfer to recipient females. Biol Reprod 2004;70:425-429.

89. Cobo A, Coello A, Remohi J, et al. Effect of oocyte vitrification on embryo quality: Time-lapse analysis and morphokinetic evaluation. Fertil Steril 2017;108:491-497.

90. Chu D, Fu L, Zhou W, Li Y. Effects of different open cryocarriers on embryo survival and clinical outcome in frozen embryotransfer cycle patients. Syst Biol Reprod Med 2018; 64:138-145.

Address correspondence to:

Sergei Amstislavsky, PhD

Department of Cryopreservation and Reproductive Technologies

Institute of Cytology and Genetics

Siberian Branch of the Russian Academy of Sciences prosp. Lavrent'eva 10 Novosibirsk 630090

Russia

E-mail: amstis@bionet.nsc.ru 